\title{
Real-World Virologic Response Rates and Prediction of Outcomes with Peginterferon Alfa-2a/Ribavirin in Hungarian HCV Genotype 1 Patients
}

\author{
Gabriella Lengyel $^{1 *}$, Judit Gervain ${ }^{2}$, Gabriella Pár ${ }^{3}$, Ferenc Szalay4, Béla Hunyady ${ }^{5}$, Ferenc Schneider ${ }^{6}$, Elemér \\ Nemesánszky ${ }^{7}$, Anna Tusnádii ${ }^{8}$ Tivadar Bányai ${ }^{9}$, Katalin Gyulay ${ }^{10}$ and István Tornai ${ }^{11}$ \\ ${ }^{1} 2^{\text {nd }}$ Department of Medicine, Semmelweis University, Budapest, 1088, Hungary \\ ${ }^{2}$ Sub-Department of Hepato-Pancreatology and Molecular Diagnostic Laboratory, Department of Internal Medicine I, Szent Gyorgy Hospital, \\ Székesfehérvár, 8000, Hungary \\ ${ }^{3}$ First Department of Medicine, University of Pécs, Pécs, 7624, Hungary \\ ${ }^{4}$ Semmelweis University, Budapest, Hungary \\ ${ }^{5}$ Somogy County Kaposi Mór Teaching Hospital, Kaposvár and University of Pécs, Pécs, 7624, Hungary \\ ${ }^{6}$ Department of Infectology, Markusovszky Teaching Hospital, Szombathely, 9700, Hungary \\ ${ }^{7}$ St John's Hospital, Department of Gastroenterology, Budapest, 1125, Hungary \\ ${ }^{8}$ Infectology Department, Hetényi Géza Hospital, Szolnok, 5000, Hungary \\ ${ }^{9}$ Department of Infectology, Pándy Kálmán Hospital, Gyula, 5700, Hungary \\ ${ }^{10}$ Roche Hungary Ltd, Budaörs, 2040, Hungary \\ ${ }^{11}$ University of Debrecen, Clinical Center, Institute of Internal Medicine, Division of Gastroenterology, Debrecen, 4032, Hungary
}

Received: October 15, 2014; Accepted: November 28, 2014; Published: December 10, 2014

*Corresponding author: Gabriella Lengyel, 2nd Dept. of Medicine, Semmelweis University, Budapest, 1088, Hungary, Tel: +36-30-9846-953; Fax: +361317-4548; E-mail: lengyel.gabriella@med.semmelweis-univ.hu

\begin{abstract}
Aim: Dual peginterferon/ribavirin therapy remains a viable option for patients with chronic hepatitis $\mathrm{C}$, because of the high cost of Direct-acting Antiviral Agents (DAA). We assessed real-life practice and treatment outcomes in Hungarian treatment-naive HCV genotype 1-infected patients who received peginterferon alfa-2a/ ribavirin treatment.

Methods: This analysis of patients enrolled in Hungary as part of a large, multinational cohort study (PROPHESYS) included treatment-naive patients with HCV genotype 1 mono-infection who were prescribed peginterferon alfa-2a plus ribavirin.

Results: Of 654 patients included in the analysis, $68 \%$ completed $\geq 80 \%$ of the planned duration of treatment $(93 \%$ and $87 \%$ received $\geq 80 \%$ of the planned doses of peginterferon alfa-2a and ribavirin, respectively) and $23 \%$ stopped treatment prematurely because of the insufficient virologic response. Virologic response rates (HCV RNA $<50 \mathrm{IU} / \mathrm{mL}$ ) were $20.3 \%, 55.2 \%$, and $63.3 \%$ by Week 4,12 , and at the end of treatment (EOT), respectively, and a sustained virologic response 24 weeks post-treatment (SVR24) was achieved in $45.9 \%$ of patients. In patients with a virologic response at EOT, the relapse rate was $27.4 \%$. SVR2 4 rates were $63 \%$ in patients who received $\geq 80 \%$ of the planned treatment and $55 \%$ in patients with lower exposure. Treatment was prolonged to $\geq 72$ weeks in 51 patients with HCV RNA $\geq 50 \mathrm{IU} / \mathrm{mL}$ at Week 12 , and $<50 \mathrm{IU} / \mathrm{mL}$ at Week 24 , among whom the SVR24 rate was $35 \%$.
\end{abstract}

Conclusion: This analysis shows that SVR24 rates achieved in randomized trials can be reproduced in real-world settings by maintaining high rates of adherence and compliance with responseguided therapy.

Keywords: Hungary; Peginterferon alfa-2a/Ribavirin; Predictive value; PROPHESYS; Real-world; Virologic response

\section{Introduction}

By examining treatment patterns and outcomes in routine clinical practice, observational cohort studies have certain advantages over randomized clinical trials [1]. As such, they generally have a broader scope than that of randomized trials. Moreover, cohort studies enroll diverse populations rather than the homogenous, strictly selected study populations typical of randomized trials. Thus, the results of cohort studies indicate how well the results of randomized trials can be translated into meaningful outcomes in the "real world".

The PROPHESYS cohorts evaluated standard treatment with peginterferon alfa/ribavirin for chronic hepatitis C [2]. The study is noteworthy for its size and scope - more than 7,000 patients were enrolled from 19 countries across several continents - and for showing that Sustained Virologic Response (SVR) rates achieved in everyday clinical practice are similar to those reported in large international clinical trials [2].

The database from this large cohort study makes it possible to examine treatment outcomes among and within participating countries. Hungary has a well-developed network of specialist centers that diagnose and treat chronic hepatitis $\mathrm{C}$ according to national guidelines [3]. These guidelines are updated annually at a Consensus Meeting and take into account international guidelines, recently published evidence, and cost-effectiveness data. Once agreed upon, the revised guidelines are forwarded to the Ministry of Health for approval and official publication. 
Within the PROPHESYS database, approximately 15\% of HCV genotype 1 patients receiving peginterferon alfa-2a/ ribavirin $(654 / 4,247)$ were from Hungarian centers; therefore, the database provides an opportunity to assess real-life practice and treatment outcomes in treatment-naive patients with HCV genotype 1 mono-infection who received treatment with peginterferon alfa-2a/ribavirin in Hungary.

\section{Methods}

The study design and primary results of the prospective, international PROPHESYS cohorts are reported elsewhere [2]. Briefly, a total of 7,163 treatment-naive patients with HCV mono-infection from 19 countries who were treated with peginterferon alfa/ribavirin were enrolled into three cohorts (PROPHESYS 1, 2, or 3). Patients eligible for enrollment were HCV RNA-positive adults aged 18 years or older who had been prescribed peginterferon alfa/ribavirin in accordance with the local summary of product characteristics [2].

This analysis of patients enrolled in Hungary as part of PROPHESYS 1 (www.clinicaltrials.gov: NCT01070550) included treatment-naive patients with HCV genotype 1 mono-infection who were prescribed peginterferon alfa-2a (40KD) (PEGASYS ${ }^{\circledR}$, Roche, Basel, Switzerland) plus ribavirin. There were few ( $n$ =4) patients infected with genotypes other than genotype 1 to extend the current analysis to other genotypes. The prescribed treatment was at the sole discretion of the physician, and patients were included in PROPHESYS only after the choice of treatment had been made. Patients who had previously received interferonbased treatment and those co-infected with HBV or HIV was excluded, and all contraindications in the Hungarian summary of product characteristics for the study drugs were adhered to. The analysis population reported here consisted of all patients who received $\geq 1$ dose of peginterferon alfa- $2 \mathrm{a}$ /ribavirin, had a baseline HCV RNA titer $\geq 50 \mathrm{IU} / \mathrm{mL}$ and had $\geq 1$ post-baseline HCV RNA test result.

Data was captured on an electronic Case Report Form (eCRF). In addition to baseline factors and treatment outcomes, treating physicians recorded details of treatment such as the planned treatment regimen, the actual treatment regimen, and the reasons for modifying the treatment regimen.

Cumulative exposure to peginterferon alfa-2a and ribavirin was expressed as percentage of the planned dose received by a patient (i.e. $100 \times$ actual cumulative dose/(dose $\times$ intended treatment duration recorded at the start of treatment). If for a patient the treatment duration was shorter than the intended treatment duration, the reason for premature discontinuation was recorded (e.g. adverse events, insufficient viral response, etc.).

The PROPHESYS cohort was conducted in accordance with the Declaration of Helsinki. Study protocols were approved by the Ethics Committees of each center. Each patient, provided informed consent before enrollment.

\section{Outcomes}

HCV RNA levels were determined in local laboratories by COBAS AmpliPrep/COBAS TaqMan ${ }^{\circledR} \mathrm{HCV}$ at baseline, at Week 4 and Week 12 during treatment, at the end of treatment, and at Week 24 of untreated follow-up and recorded in the eCRF. Virologic response at any time point was defined as HCV RNA < $50 \mathrm{IU} / \mathrm{mL}$.

Four non-overlapping categories were used to describe the virologic response during the first 12 weeks of treatment: 1) Rapid Virologic Response (RVR), defined as HCV RNA < 50 IU/ $\mathrm{mL}$ by Week 4 (Days 2-43); 2) complete Early Virologic Response (cEVR), defined as HCV RNA < $50 \mathrm{IU} / \mathrm{mL}$ by Week 12 (Days 4499) in a patient who did not achieve an RVR; 3) partial Early Virologic Response (pEVR), defined as at least a 2-log decrease in HCV RNA by Week 12 (Days 2-99) in a patient who did not achieve an RVR or cEVR (i.e. these patients have HCV RNA levels $\geq 50$ IU/mL by Day 99); and 4) no RVR/EVR (i.e. no RVR, no cEVR, and no pEVR, but at least one HCV RNA measurement within the first 12 weeks).

SVR24 was defined as last HCV RNA $<50 \mathrm{IU} / \mathrm{mL} 24$ weeks after EOT ( $\geq 140$ days after the last dose), respectively.

Relapse was defined as serum HCV RNA $\geq 50 \mathrm{IU} / \mathrm{mL}$ during follow-up in a patient with an EOT response. Only patients with an EOT response $(\mathrm{HCV}<50 \mathrm{IU} / \mathrm{mL})$ and at least one posttreatment HCV RNA result were included in the calculation of the relapse rate. Positive Predictive Value (PPV) was defined as the probability that a patient with a specific on-treatment virologic response would achieve an SVR24. Associations between baseline factors and SVR24 were examined by Multiple Logistic Regression (MLR) analysis. All statistical tests are performed two-sided and a $p$-value of $<0.05$ is considered statistically significant. However, all statistical tests are of exploratory nature and a significant difference should be interpreted cautiously.

\section{Results}

\section{Patients}

A total of $654 \mathrm{HCV}$ genotype 1 patients from 32 sites in Hungary received at least one dose of peginterferon alfa- $2 \mathrm{a} /$ ribavirin and were included in the analysis. Patients were enrolled, treated, and tested for their HCV RNA levels between June 2007 and March 2011. The median age of patients was 49 years, the male/ female ratio was $44.6 / 55.4,98.8 \%$ of patients were Caucasian, $53.1 \%$ had a body weight $<75 \mathrm{~kg}$ and $68.0 \%$ had a high baseline HCV RNA level > 800,000 IU/mL (Table 1). Hepatic fibrosis was assessed by either liver biopsy or a non-invasive method prior to therapy in $52.8 \%$ of patients and, overall, $16.8 \%$ of patients had confirmed bridging fibrosis or cirrhosis (Table 1).

While this analysis focuses on data from Hungary, a comparison of the baseline characteristics of patients enrolled at Hungarian and non-Hungarian study sites show that the median age, body mass index, and the number of patients 
Table 1: Baseline characteristics of HCV genotype 1, Mono-infected patients treated with Peginterferon alfa-2a and Ribavirin

\begin{tabular}{|c|c|c|c|c|}
\hline \multicolumn{2}{|c|}{ Characteristic $^{\dagger}$} & $\begin{array}{c}\text { Patients enrolled at } \\
\text { Hungarian sites }(N=654)\end{array}$ & $\begin{array}{c}\text { Patients enrolled at non- } \\
\text { Hungarian sites } \\
(N=3,593)\end{array}$ & $\begin{array}{l}\text { P-value for differences } \\
\text { between the two cohorts }\end{array}$ \\
\hline \multicolumn{2}{|c|}{ Male/female gender, $n$ (\%) } & $292(44.6) / 362(55.4)$ & $\begin{array}{r}1,952(54.3) / \\
1,641(45.7)\end{array}$ & $<0.0001^{\#}$ \\
\hline \multicolumn{5}{|l|}{ Race/ethnicity, $n(\%)$} \\
\hline \multicolumn{2}{|l|}{ White/Caucasian } & $646(98.8)$ & $3068(85.5)$ & \multirow{4}{*}{$<0.0001^{\#}$} \\
\hline \multicolumn{2}{|l|}{ Black } & $1(0.2)$ & $201(5.6)$ & \\
\hline \multicolumn{2}{|l|}{ Asian } & $1(0.2)$ & $52(1.4)$ & \\
\hline \multicolumn{2}{|l|}{ Other } & $6(0.9)$ & $267(7.4)$ & \\
\hline \multicolumn{2}{|c|}{ Median age, years (range) } & $49.0(18-79)$ & $48.0(18-86)$ & $0.7984^{\&}$ \\
\hline \multirow{3}{*}{ Age, $n(\%)$} & $\leq 45$ years & $229(35.0)$ & $1455(40.5)$ & \multirow{3}{*}{$\begin{array}{l}0.0779^{\&} \\
0.0003^{\#}\end{array}$} \\
\hline & $45-65$ years & $406(62.1)$ & $1,949(54.2)$ & \\
\hline & $>65$ years & $19(2.9)$ & $189(5.3)$ & \\
\hline \multirow{2}{*}{ Body weight, $n(\%)$} & $<75 \mathrm{~kg}$ & $347(53.1)$ & $1,879(52.6)$ & \multirow{2}{*}{$0.8251^{\#}$} \\
\hline & $\geq 75 \mathrm{~kg}$ & $307(46.9)$ & $1,694(47.4)$ & \\
\hline \multicolumn{2}{|c|}{ Median BMI, kg/m² (range) } & $25.7(17.3-50.0)$ & $25.4(15.0-56.6)$ & $0.1289^{\&}$ \\
\hline \multirow{4}{*}{ BMI, $n(\%)$} & $\leq 20 \mathrm{~kg} / \mathrm{m}^{2}$ & $40(6.1)$ & $174(4.9)$ & \multirow{4}{*}{$\begin{array}{l}0.2993^{\&} \\
0.1723^{\#}\end{array}$} \\
\hline & $>20-25 \mathrm{~kg} / \mathrm{m}^{2}$ & $248(37.9)$ & $1,461(41.2)$ & \\
\hline & $>25-30 \mathrm{~kg} / \mathrm{m}^{2}$ & $243(37.2)$ & $1329(37.5)$ & \\
\hline & $>30 \mathrm{~kg} / \mathrm{m}^{2}$ & $123(18.8)$ & $581(16.4)$ & \\
\hline \multicolumn{4}{|l|}{ Liver fibrosis, ${ }^{\ddagger} n(\%)$} & \multirow{4}{*}{$<.0001^{\#}$} \\
\hline \multicolumn{2}{|c|}{ Bridging fibrosis/cirrhosis } & $110(16.8)$ & $961(26.7)$ & \\
\hline \multicolumn{2}{|l|}{ No cirrhosis } & $235(35.9)$ & $1989(55.4)$ & \\
\hline \multicolumn{2}{|l|}{ Not assessed/missing } & $309(47.2)$ & $643(17.9)$ & \\
\hline \multicolumn{2}{|l|}{ ALT quotient, $n(\%)$} & & & \\
\hline \multicolumn{2}{|l|}{ Mean \pm SD } & $2.1 \pm 1.6$ & $2.3 \pm 1.9$ & $0.0969^{\&}$ \\
\hline \multicolumn{2}{|l|}{$\leq 1, n(\%)$} & $150(22.9)$ & $778(22.1)$ & \multirow{3}{*}{$\begin{array}{l}0.0832^{\&} \\
0.0623^{\#}\end{array}$} \\
\hline \multicolumn{2}{|l|}{$>1-3, n(\%)$} & $388(59.3)$ & $1970(56.0)$ & \\
\hline \multicolumn{2}{|l|}{$>3, n(\%)$} & $116(17.7)$ & $767(21.8)$ & \\
\hline \multicolumn{2}{|l|}{ Mean AST, IU/L \pm SD } & $43.0 \pm 37.8$ & $45.7 \pm 34.9$ & $0.0035^{\&}$ \\
\hline Mean platelets, $\mathrm{x} 10^{9} /$ & $\pm \mathrm{SD}$ & $207 \pm 67$ & $215 \pm 72$ & $0.0234^{\&}$ \\
\hline Platelets $\times 10^{9} / \mathrm{L}, n / N$ & & & & \\
\hline$<140$ & & $105 / 646(16.3)$ & $485(14.0)$ & $0.1273^{\#}$ \\
\hline$\geq 140$ & & $541 / 646(83.7)$ & $2988(86.0)$ & $0.12 / 3$ \\
\hline Mean HCV RNA level, & $g_{10} I U / m L \pm S D$ & $6.09 \pm 0.85$ & $5.99 \pm 0.84$ & $0.0007^{\&}$ \\
\hline & $\leq 400,000$ & $135 / 653(20.7)$ & $958 / 3549(27.0)$ & \\
\hline HCV RNA, IU $/ \mathrm{mL} n / N$ & $>400,000-600,000$ & $46 / 653(7.0)$ & $224 / 3549(6.3)$ & $0.0009^{\&}$ \\
\hline & $>600,000-800,000$ & $28 / 653(4.3)$ & $182 / 3549(5.1)$ & \\
\hline & $>800,000$ & $444 / 653(68.0)$ & $2185 / 3549(61.6)$ & \\
\hline
\end{tabular}

${ }^{\dagger}$ Some categories do not add up to the total number of patients because of missing values

${ }^{\ddagger}$ Among patients enrolled at Hungarian sites a total of 320 patients (48.9\%) were evaluated by liver biopsy and 25 patients (3.8\%) were evaluated by a non-invasive method (15 by Fibroscan), at non-Hungarian sites 2,272 patients (63.3\%) were evaluated by liver biopsy and 681 patients (19.0\%) were evaluated by a non-invasive method (603 by Fibroscan)

ALT: Alanine Amino Transferase; ALT quotient: ALT value divided by the upper limit of normal range of the local laboratory; BMI: Body Mass Index; SD: Standard Deviation

\# $\mathrm{p}$-value of Chi-Square test

\&p-value for Wilcoxon rank-sum test

with a low platelet count $\left(<140 \times 10^{9} / \mathrm{L}\right)$ were similar in both patient groups (Table 1). In contrast, among those enrolled from Hungarian sites, a higher proportion were female $(55.3 \%$ vs $45.7 \%)$ and Caucasian (98.8\% vs $85.5 \%)$ and fewer had a pre-treatment fibrosis assessment $(52.8 \%$ vs $82.1 \%)$; of those with a pre-treatment fibrosis assessment, the proportion with bridging fibrosis/cirrhosis was lower among patients enrolled at Hungarian study sites (16.8\% vs $26.7 \%)$. Furthermore, the proportion of patients with HCV RNA values $>800,000 \mathrm{IU} / \mathrm{mL}$ was higher in Hungarian patients (68.0\% vs 61.6\%) (Table 1$)$. 


\section{Treatment}

Most patients from Hungary were assigned to treatment with peginterferon alfa-2a at a dosage of $180 \mu \mathrm{g} /$ week (98.3\%) in combination with ribavirin at a dosage of 1000 or $1200 \mathrm{mg} /$ day $(93.9 \%)$ for a planned duration of 48 weeks (89.1\%) as per the label (Table 2). The mean initial dose of ribavirin was 14.7 $\mathrm{mg} / \mathrm{kg} /$ day (range 9 to $24 \mathrm{mg} / \mathrm{kg} /$ day). A total of 444 patients $(67.9 \%)$ completed at least $80 \%$ of the planned duration of treatment, of whom $93.0 \%$ (413) received at least $80 \%$ of the planned dose of peginterferon alfa-2a and $87.4 \%$ (388) received at least $80 \%$ of the planned dose of ribavirin.

Of 654 patients included in the analysis, a total of 235 individuals $(35.9 \%)$ stopped treatment prematurely (Table 3). The most common reason for premature withdrawal from treatment was insufficient virologic response. Within the PROPHESYS database, a higher proportion of Hungarian than non-Hungarian patients withdrew prematurely due to insufficient virologic response (20.2\% [132/654] vs $12.4 \%$ [447/3,593]) (Chi-Square test, $p<0.0001$; unpublished data). Only five patients with an EOT response had missing follow-up results for assessment of SVR24. Adverse events or laboratory abnormalities that led to premature withdrawal from treatment with peginterferon included neutropenia $(n=6)$, flu-like symptoms $(n=4)$, thrombocytopenia $(n=4)$, depression $(n=2)$, and other events $(n=40)$. In addition, treatment with ribavirin was withdrawn prematurely in 14 patients because of anemia.

\section{Efficacy}

Virologic response rates increased over time and were $20.3 \%, 55.2 \%$, and $63.3 \%$ by Week 4 , by Week 12 , and at EOT, respectively, and an SVR24 was achieved in 45.9\% (300/654) of patients (Figure 1). In patients with a virologic response at EOT, the relapse rate was $27.4 \%(111 / 405)$.

When the analysis was restricted to patients who received treatment for at least $80 \%$ of the intended treatment duration $(n=444)$, on-treatment virologic response rates in the first 12 weeks were similar, if not higher in patients who received $<80 \%$ of the planned dose of both peginterferon alfa-2a and ribavirin ( $n=74$ ) than in those who received $\geq 80 \%$ of the planned dose $(n=370)$. However, virologic response rates at EOT and SVR24 rates were higher in patients who received $\geq 80 \%$ of the planned dose (EOT 86.8\%; SVR24 63.0\% [233/370] vs 73.0\% and 55.4\% [41/74], respectively, in patients who received $<80 \%$ of the planned dose) (Figure 2a). Relapse rates were similar in patients who received $\geq 80 \%$ of the planned dose (27.9\% [89/319]) and in those who received $<80 \%$ of the planned dose $(29.6 \%$ [16/54]).

Among patients aged 40 years or younger $(n=150)$, virologic response rates were consistently higher at all time points than in older patients $(n=504)$. Final SVR24 rates were $64.7 \%$ in patients aged 40 years or younger and $40.3 \%$ in patients older than 40 years $(p<0.0001$; Figure $2 \mathrm{~b})$. Similarly, virologic response rates were consistently higher in patients without cirrhosis $(n=235)$ than in patients with cirrhosis $(n=110)$ and final SVR24 rates
Table 2: Treatment Data

\begin{tabular}{|c|c|}
\hline Characteristic & Patients, $n(\%)$ \\
\hline \multicolumn{2}{|c|}{ Initial therapy $(n=654)$} \\
\hline \multicolumn{2}{|l|}{ Peginterferon alfa-2a dose, $\mu \mathrm{g} /$ week } \\
\hline 90 & $1(0.2)$ \\
\hline 135 & $10(1.5)$ \\
\hline 180 & $643(98.3)$ \\
\hline \multicolumn{2}{|l|}{ Ribavirin dose, mg/day } \\
\hline 600 & $2(0.3)$ \\
\hline 800 & $30(4.6)$ \\
\hline 1000 & $335(51.2)$ \\
\hline 1200 & $279(42.7)$ \\
\hline 1400 & $7(1.1)$ \\
\hline 1600 & $1(0.2)$ \\
\hline \multicolumn{2}{|l|}{ Intended treatment duration, weeks } \\
\hline 24 & $6(0.9)$ \\
\hline 48 & $583(89.1)$ \\
\hline 52 & $65(9.9)$ \\
\hline \multicolumn{2}{|c|}{ Duration of treatment $(n=654)$} \\
\hline $\begin{array}{l}\text { Mean duration of treatment, weeks } \pm \\
\text { SD (median; range) }\end{array}$ & $45.0 \pm 17.4(48 ; 4-87)$ \\
\hline$<24$ & $60(9.2)$ \\
\hline 24 & $32(4.9)$ \\
\hline$>24$ to $<48$ & $159(24.3)$ \\
\hline 48 & $98(15.0)$ \\
\hline$>48$ to $<52$ & $80(12.2)$ \\
\hline 52 & $74(11.3)$ \\
\hline$>52$ to $<72$ & $63(9.6)$ \\
\hline 72 & $45(6.9)$ \\
\hline$>72$ & $43(6.6)$ \\
\hline \multicolumn{2}{|c|}{ Treatment exposure $(n=444)^{\dagger}$} \\
\hline \multicolumn{2}{|l|}{ Peginterferon alfa-2a dose } \\
\hline $\begin{array}{l}\text { Mean cumulative dose administered, } \\
\mu \mathrm{g} \pm \mathrm{SD}\end{array}$ & $9,365 \pm 2,181$ \\
\hline \multicolumn{2}{|l|}{$\begin{array}{l}\text { Percentage of target dose } \\
\text { administered }\end{array}$} \\
\hline$<60$ & $9(2.0)$ \\
\hline 60 to $<80$ & $22(5.0)$ \\
\hline 80 to $<95$ & $52(11.7)$ \\
\hline$\geq 95$ & $361(81.3)$ \\
\hline \multicolumn{2}{|l|}{ Ribavirin dose } \\
\hline $\begin{array}{l}\text { Mean cumulative dose administered, } \\
\mu \mathrm{g} \pm \mathrm{SD}\end{array}$ & $380,727 \pm 110,731$ \\
\hline \multicolumn{2}{|l|}{$\begin{array}{l}\text { Percentage of target dose } \\
\text { administered }\end{array}$} \\
\hline$<60$ & $20(4.5)$ \\
\hline 60 to $<80$ & $36(8.1)$ \\
\hline 80 to $<95$ & $50(11.3)$ \\
\hline$\geq 95$ & $338(76.1)$ \\
\hline
\end{tabular}

${ }^{\dagger}$ Only patients who completed at least $80 \%$ of the intended treatment duration were included in calculations of treatment exposure. SD-standard deviation 
Table 3: Reasons for premature withdrawal from treatment.

\begin{tabular}{|l|c|}
\hline Reason for withdrawal & Patients, $\boldsymbol{n}$ (\%) \\
\hline Adverse events & $56(8.6)$ \\
\hline Efficacy-related reasons & \\
\hline Insufficient viral response & $132(20.2)$ \\
\hline Other efficacy related reasons $^{\dagger}$ & $18(2.7)$ \\
\hline Other reason $^{\ddagger}$ & $29(4.4)$ \\
\hline Total & $235(35.9)$ \\
\hline
\end{tabular}

${ }^{\dagger}$ Reasons cited by physicians include: 1$)$ viral response at Week 4 ( $n=17$; $2.6 \%) ; 2)$ viral response at Week $12(n=1 ; 0.2 \%)$.

* Reasons cited by physicians include: 1$)$ failure to return $(n=10 ; 1.5 \%)$; 2) refused treatment/decision of patient $(n=9 ; 1.4 \%) ; 3)$ unknown/ unspecified $(n=4 ; 0.6 \%) ; 4)$ organizational reasons $(n=3 ; 0.5 \%) ; 5)$ consent for observation withdrawn $(n=1 ; 0.2 \%) ; 6)$ drug abuse $(n=1$; $0.2 \%) ; 7)$ mistake/misunderstanding $(n=1 ; 0.2 \%)$

Table 4: Reasons for Treatment Prolongation by Achievement of Virologic Response by Week 12.

\begin{tabular}{|l|l|l|}
\hline $\begin{array}{l}\text { Reason for } \\
\text { prolongation, } \boldsymbol{n}(\mathbf{\%})\end{array}$ & $\begin{array}{l}\text { Patients with a } \\
\text { complete virologic } \\
\text { response by Week } \\
\mathbf{1 2}^{\dagger} \\
(\boldsymbol{n}=\mathbf{3 6 1 )}\end{array}$ & $\begin{array}{l}\text { Patients without_a } \\
\text { virologic response by } \\
\text { Week 12 } \\
(\boldsymbol{n}=\mathbf{2 9 0})\end{array}$ \\
\hline Adverse events & $2(0.6)$ & 0 \\
\hline $\begin{array}{l}\text { Efficacy-related } \\
\text { reasons }\end{array}$ & $35(9.7)$ & $70(24.1)$ \\
\hline Other reasons & $14(3.9)$ & $1(0.3)$ \\
\hline Total & $51(14.1)$ & $71(24.5)$ \\
\hline
\end{tabular}

+ Patients who achieved an RVR or cEVR

${ }^{*}$ Patients who achieved a pEVR or who did not achieve an RVR/EVR

$\S$ Reasons cited by physicians include 1) extension of the viral-free treatment period; 2) no viral response at Week 12;3) interruption of treatment; 4) slow virologic response; 5) no viral response at end of treatment.

were $56.6 \%$ in non-cirrhotic patients and $31.8 \%$ in patients with cirrhosis ( $p<0.0001$; Figure 2c).

On-treatment prediction of SVR24: A total of 529 (80.9\%) patients achieved at least a 2-log drop in HCV RNA level during the first 12 weeks of treatment $(20.3 \%, 34.9 \%$, and $25.7 \%$ achieved an RVR, cEVR, and pEVR, respectively). SVR24 rates in patients by on-treatment response category is shown in Figure 3. The PPV of an RVR, cEVR, and pEVR for SVR24 was 85.7\%, 65.4\%, and $20.8 \%$, respectively. Overall, 361 (55.2\%) patients achieved a virologic response by Week 12 (RVR or cEVR) and an SVR24 was achieved in $263(72.9 \%)$ of these individuals. In contrast, only 37 of the 290 patients (12.8\%) who did not achieve a complete virologic response by Week 12 (pEVR or no RVR/EVR) achieved an SVR24.

Within the subgroup of patients with a pEVR $(n=168)$, the PPV of a pEVR for SVR24 was $20.8 \%$ (i.e. $79.2 \%$ of patients did not achieve an SVR24), while among patients without an RVR or EVR (i.e. HCV RNA > $50 \mathrm{IU} / \mathrm{mL}$ at Week 12) only 1.6\% (2/122) achieved an SVR24 (i.e. the NPV of not achieving an RVR or EVR was $98.4 \%$ ).

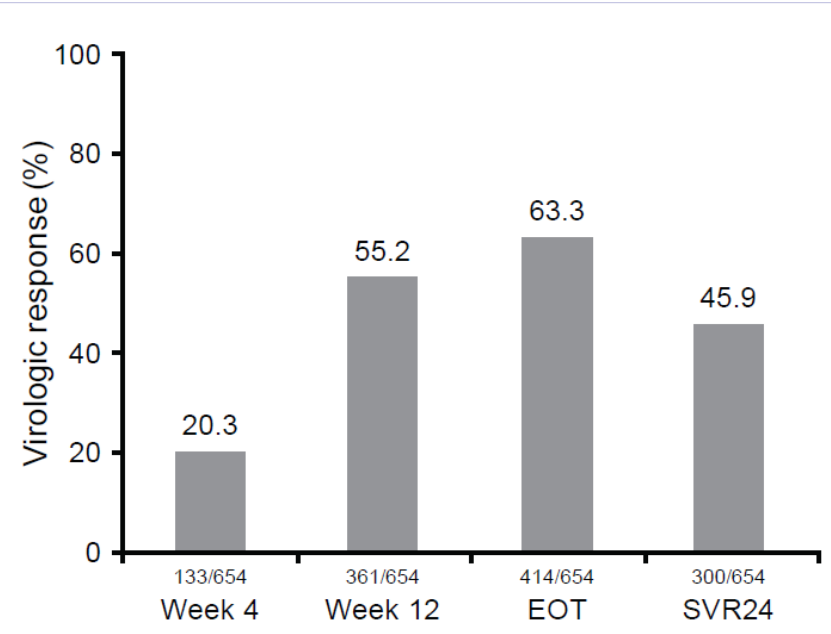

Figure 1: Virologic response over time in HCV genotype 1 Hungarian patients.

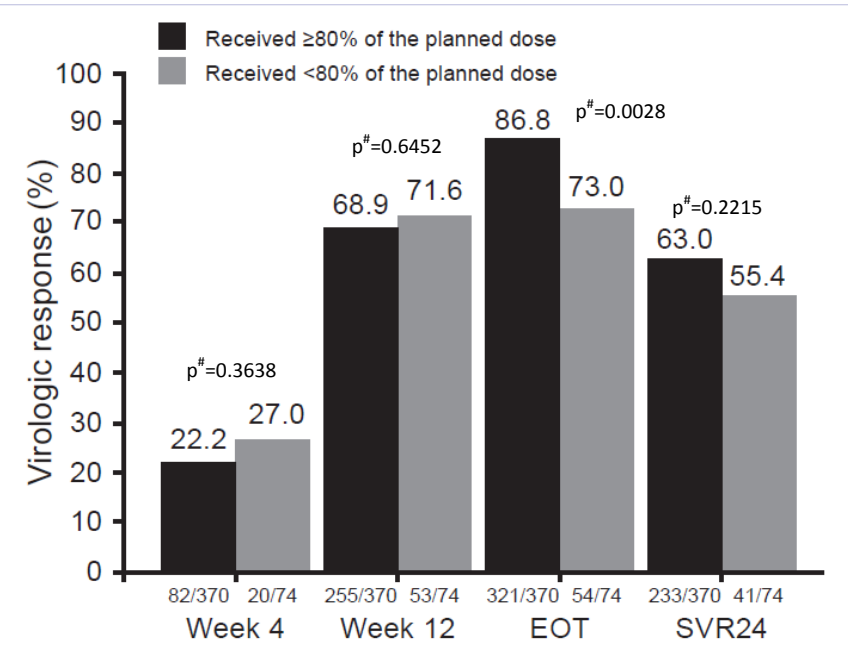

Figure 2a: Virologic response over time according to received in relation to planned dose of both peginterferon alfa-2a and Ribavirin. Analysis restricted to those patients who completed $\geq 80 \%$ of the intended treatment duration.

\#p-value of Chi-Square test

Treatment extension: Overall treatment was prolonged in a total of 122 of 651 (18.7\%) patients who had a virologic response documented within the first 12 weeks (Table 4). Among these individuals, physicians cited efficacy-related reasons as the reason for treatment prolongation in 105 of 651 (16.1\%) patients. In comparison, treatment was prolonged for efficacy-related reasons in $8.4 \%$ of corresponding patients $(303 / 3,593)$ who were enrolled at non-Hungarian study sites within PROPHESYS (Chi-Square test, $p<0.0001$; unpublished data).

A total of 97 patients had a slow virologic response characterized by no RVR/cEVR at Week 12 and a virologic response ( $\mathrm{HCV}$ RNA $<50 \mathrm{IU} / \mathrm{mL}$ ) at Week 24. Among these 
patients, 51 were treated for $\geq 72$ weeks (range: $72-83$ weeks) and 46 were treated for $<72$ weeks (24-71 weeks). SVR24 rates in these two groups were $35.3 \%(18 / 51)$ and $21.7 \%(10 / 46)$, respectively (Chi-Square test, $p=0.1413$ ). Only one of the 46 patients treated for $<72$ weeks received treatment for a period that was $>52$ weeks.

Predictors of SVR24: Baseline factors that had a statistically significant positive association with higher SVR24 rates in the MLR analysis included younger age (Odds Ratio [OR] 1.18 per 10year decrement, 95\% Confidence Interval [CI] 1.01-1.38), lower serum HCV RNA level (OR 2.23 per $1-\log _{10}$ decrement, CI 1.772.80), absence of cirrhosis (OR 1.88 for no cirrhosis vs cirrhosis

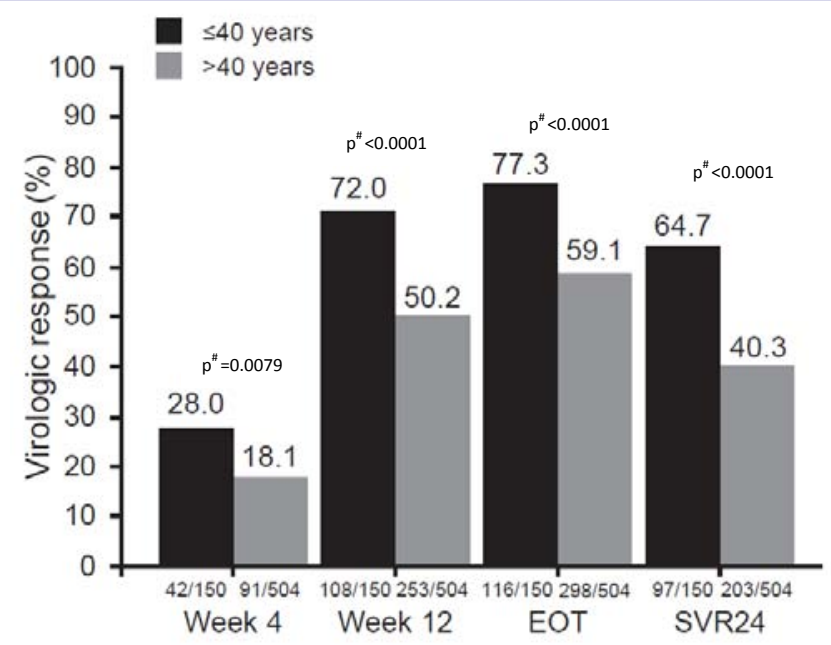

Figure 2b: Virologic response over time according to age. \#p-value of Chi-Square test

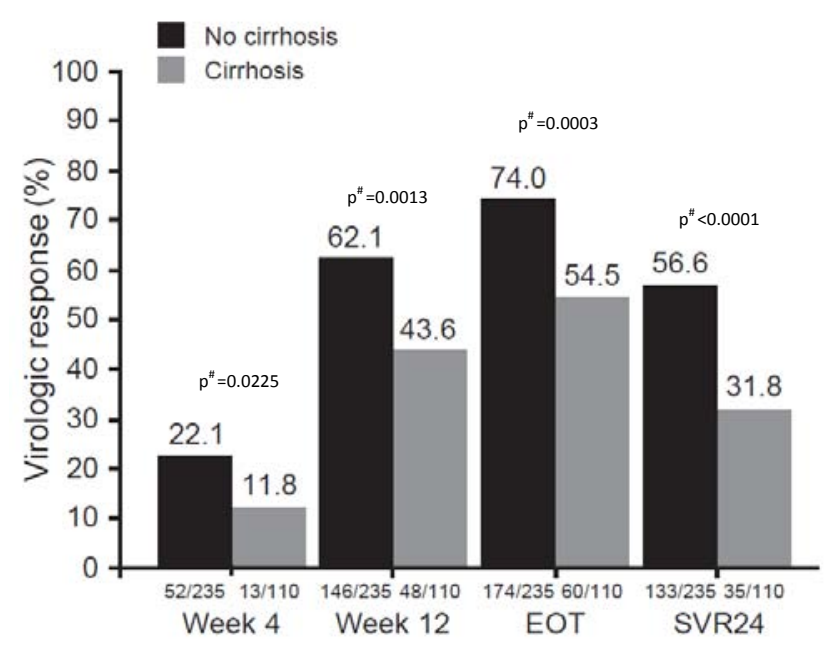

Figure 2c: Virologic response over time according to extent of hepatic fibrosis. Only patients with a baseline fibrosis assessment are included in calculations (309 patients were not assessed or had missing baseline data).

\#p-value of Chi-Square test

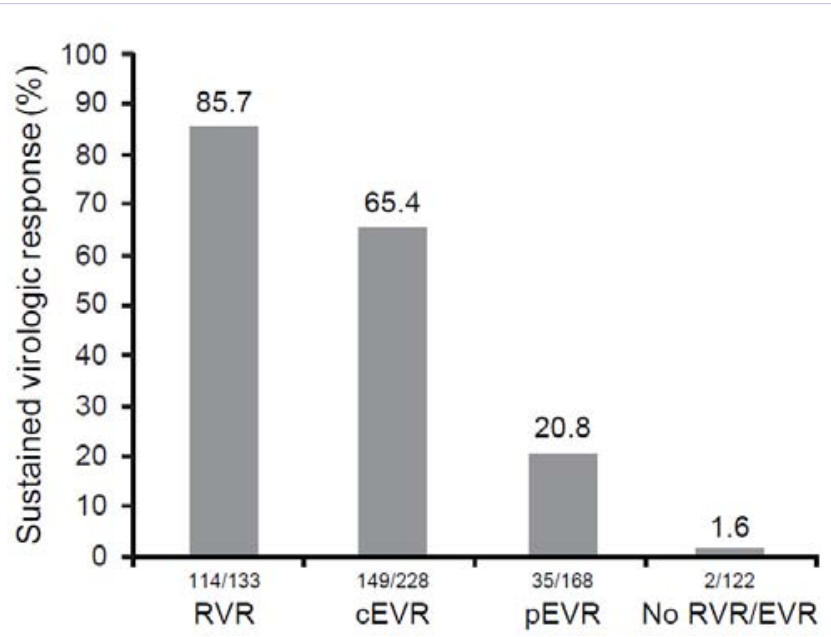

Figure 3: SVR24 rates according to on-treatment virologic response category. Three patients (3/654) had missing on-treatment response during the first 12 week.

[CI 1.11-3.20]), and higher platelet count (OR 3.49 for $\geq 140$ to $<$ $180 \times 10^{9} / \mathrm{L}$ vs < $140 \times 10^{9} / \mathrm{L}$ [CI 1.83-6.66]; OR 4.99 for $\geq 180 \times$ $10^{9} / \mathrm{L}$ vs $<140 \times 10^{9} / \mathrm{L}$ [CI 2.80-8.91]).

\section{Discussion}

The results of this PROPHESYS subanalysis show that, in Hungary, $45.9 \%$ of treatment-naive HCV genotype- 1 infected patients treated with peginterferon alfa-2a/ribavirin achieved an SVR24. This SVR24 rate is higher than that achieved in HCV genotype 1 patients in the overall PROPHESYS cohorts, which pooled data from 19 countries (41.8\% overall [2]; 41.7\% when non-Hungarian genotype 1 patients receiving peginterferon alfa$2 \mathrm{a}$ /ribavirin are compared; Chi-Square test; $p=0.0466$ ).

The relatively high SVR24 rates observed in this study may be attributed, in part at least, to a combination of high rates of treatment completion and follow-up (i.e. few patients were lost post-treatment) and the use of Response Guided Therapy (RGT). Other factors that may have contributed to this difference in SVR24 rates include the higher proportion of Caucasian patients and the lower proportion of patients with advanced fibrosis at Hungarian study sites. However, a considerably lower proportion of patients had a fibrosis assessment performed at Hungarian than non-Hungarian study sites, and the proportion of patients with low platelet counts, typical of patients with cirrhosis, was similar in these two populations. Thus, one must be cautious before concluding that the true prevalence of advanced fibrosis was lower in patients enrolled at Hungarian sites.

Among Hungarian patients included in this analysis, 68\% (444/654) completed at least $80 \%$ of the planned duration of treatment, among whom $87 \%$ received at least $80 \%$ of the planned ribavirin dose. Analyses of data from large randomized clinical trials have shown that exposure to at least $60 \%$ of the target dose of ribavirin is associated with higher SVR24 rates [4]. However, in the overall PROPHESYS cohorts (excluding Hungarian centers), adherence was just as high: 70\% completed 
at least $80 \%$ of planned duration of treatment, among whom $92 \%$ received at least $80 \%$ of the planned ribavirin dose (unpublished data).

Adherence to national guidelines and the use of RGT may have contributed to the comparatively high SVR24 rates. Hungarian guidelines for the treatment of chronic hepatitis C recommend monitoring the virologic response at Weeks 4 and 12 and modifying the treatment regimen accordingly [3]. Among treatment-naive genotype 1 patients in PROPHESYS, the rate of treatment prolongation for efficacy-related reasons was approximately two fold higher in Hungarian patients than in patients enrolled at non-Hungarian sites $(16 \%$ vs $8 \%, p<0.0001)$. It is also noteworthy that, although the SVR24 rate at Hungarian study sites was considerably higher than at non-Hungarian sites, a higher proportion of patients at Hungarian sites discontinued treatment prematurely due to insufficient therapeutic response than patients enrolled at non-Hungarian sites. These observations suggest that many Hungarian physicians who participated in PROPHESYS were familiar with the principles of RGT and modified treatment plans accordingly, including extending therapy when appropriate and applying stopping rules in patients who had a low probability of achieving an SVR. Indeed, soon after the initiation of PROPHESYS, the Hungarian national treatment guidelines were updated and the revised guidelines contained the concept of RGT. Based on the results of clinical studies, the revised Hungarian guidelines recommended different treatment durations for patients with rapid and slow virologic responses. For example, the guidelines recommended that treatment be shortened to 24 weeks in non-cirrhotic patients with a low baseline viral load $(\leq 400,000 \mathrm{IU} / \mathrm{mL})$ who achieved an RVR by Week 4 of treatment. For patients with at least a 2-log decrease in viral load, but who remained HCV RNA-positive at Week 12 (i.e. no cEVR or RVR), the guidelines recommended that treatment continue to Week 24, at which point the HCV RNA level was reevaluated. For patients who were HCV RNA-negative by Week 24, treatment extension to 72 weeks was recommended. As RGT was supported by the Hungarian guidelines, practically from the start of the PROPHESYS study, the concept was recommended clinical practice in Hungary and is reflected in the results of the study.

Prolongation of treatment to at least 72 weeks in patients with a slow virologic response (HCV RNA $\geq 50 \mathrm{IU} / \mathrm{mL}$ at Week 12, and $<50 \mathrm{IU} / \mathrm{mL}$ at Week 24 ) seems to be associated with a higher SVR24 rate when compared with treatment for $<72$ weeks $(35 \%$ vs $22 \%$ ), but didn't achieve statistical significance ( $p=0.1413$ ). This result falls within the range reported in patients with slow virologic responses who have been assigned to 72 weeks of therapy in randomized trials [5-10].

The findings of this study confirm that SVR24 rates decrease in proportion to the time taken to achieve an HCV RNA level $<50$ $\mathrm{IU} / \mathrm{mL}[11,12]$. SVR24 rates in patients with an RVR and a cEVR were $85.7 \%$ and $65.4 \%$, respectively. In contrast, SVR2 4 rates were considerably lower in patients with a pEVR $(20.8 \%)$ and in those with no RVR/EVR (1.6\%).
Sub analyses showed that SVR24 rates were significantly higher in younger patients and in non-cirrhotic patients. This is supported by the MLR analysis which identified younger age and absence of cirrhosis to be significantly associated with SVR24. Other baseline laboratory parameters significantly associated with SVR24 in Hungarian patients were a lower serum HCV RNA level and higher platelet count.

The results of this study are of practical value and can be used to inform treatment decisions with the approved HCV protease inhibitors, boceprevir and telaprevir, which became available and financed for a segment of Hungarian patients in 2013. Furthermore simeprevir will also be available from 2015. These protease inhibitors have the potential to significantly increase overall SVR rates and decrease the duration of treatment in treatment-naive patients with HCV genotype 1 infection [13-15]. However, protease inhibitors must be used in combination with peginterferon alfa/ribavirin, thus increasing the adverse event burden and the potential cost of treatment. This is particularly problematic in countries with limited resources for the treatment of chronic hepatitis C. If such countries adopt a policy to use protease inhibitors universally for patients with HCV genotype 1 infection, fewer patients might be treated overall.

One potential strategy for cost-effective use of protease inhibitors is to treat all treatment-naive patients with dual peginterferon alfa/ribavirin therapy and reserve protease inhibitors for those patients unlikely to achieve an SVR with dual therapy. A Hungarian analysis, which was based on a model that incorporated the results of international randomized trials, showed that SVR rates were similar, but overall drug costs were 12 to $30 \%$ lower, if all treatment-naive patients received dual peginterferon alfa/ribavirin initial therapy for 4 to 12 weeks, and only those patients without a 1-log drop in HCV RNA by Week 4 and those without at least a cEVR by Week 12 were switched to protease inhibitor-based therapy [16]. Indeed, this strategy has been incorporated into the Hungarian national guidelines, where cEVR is defined as undetectable HCV RNA [17]. Country-specific data from PROPHESYS could be used to refine projections from this model. Successful implementation of such a strategy and realisation of the projected cost savings requires all physicians to follow the proposed algorithm.

In conclusion, this subanalysis from the large PROPHESYS database shows that comparatively high SVR24 rates were achieved with the combination of peginterferon alfa-2a/ribavirin in Hungarian patients with HCV genotype 1 infection. Reasons for the relatively good overall efficacy include high rates of treatment completion and follow-up on the part of the patients enrolled in the study and with national guideline-compliant RGT by the clinicians who participated in the study.

\section{Acknowledgments}

This study was supported by F. Hoffmann-La Roche Ltd, Basel, Switzerland. Support for third-party writing assistance for this manuscript was provided by F. Hoffmann-La Roche Ltd, Basel, Switzerland. 


\section{References}

1. Sorensen HT, Lash TL, Rothman KJ. Beyond randomized controlled trials: a critical comparison of trials with nonrandomized studies. Hepatology. 2006; 44(5): 1075-1082.

2. Marcellin P, Cheinquer H, Curescu M, Dusheiko G, Ferenci P, Horban $A$, et al. High sustained virologic response rates in rapid virologic response patients in the large real-world PROPHESYS cohort confirm results from randomized clinical trials. Hepatology. 2012; 56(6): 2039-2050. doi: 10.1002/hep.25892.

3. Dalmi L, Gervain J, Hunyady B, Ibranyi E, Makara M, Par A, et al. Protocol for the treatment of chronic viral hepatitis. Orv Hetil. 2006; 147(51): 2481-2484.

4. Reddy KR, Shiffman ML, Morgan TR, Zeuzem S, Hadziyannis S, Hamzeh FM, et al. Impact of ribavirin dose reductions in hepatitis $C$ virus genotype 1 patients completing peginterferon alfa-2a/ribavirin treatment. Clin Gastroenterol Hepatol. 2007; 5(1): 124-129.

5. Berg T, von Wagner M, Nasser S, Sarrazin C, Heintges T, Gerlach T, et al. Extended treatment duration for hepatitis $\mathrm{C}$ virus type 1 : comparing 48 versus 72 weeks of peginterferon-alfa-2a plus ribavirin. Gastroenterology. 2006; 130(4): 1086-1097.

6. Buti M, Lurie Y, Zakharova NG, Blokhina NP, Horban A, Teuber G, et al. Randomized trial of peginterferon alfa-2b and ribavirin for 48 or 72 weeks in patients with hepatitis $C$ virus genotype 1 and slow virologic response. Hepatology. 2010; 52(4): 1201-1207. doi: 10.1002/ hep.23816.

7. Ferenci $P$, Laferl $H$, Scherzer TM, Maieron A, Hofer $H$, Stauber $\mathrm{R}$, et al. Peginterferon alfa-2a/ribavirin for 48 or 72 weeks in hepatitis $\mathrm{C}$ genotypes 1 and 4 patients with slow virologic response. Gastroenterology. 2010; 138(2): 503-512. doi: 10.1053/j. gastro.2009.10.058.

8. Lee SS, Sherman M, Ramji A, Greenbloom S, Elkashab M, Pluta H, et al. Randomised clinical trial: the efficacy of treatment, guided by a shorter duration of response, using peginterferon alfa-2a plus ribavirin for hepatitis $\mathrm{C}$ virus other than genotypes 2 or 3 . Aliment Pharmacol Ther 2012 ; 35(1): 37-47. doi: 10.1111/j.1365-2036.2011.04911.x.
9. Sarrazin C, Berg T, Cornberg M, Dollinger M, Ferenci P, Hinrichsen $\mathrm{H}$, et al. [Expert opinion on boceprevir- and telaprevir-based triple therapies of chronic hepatitis C]. Z Gastroenterol. 2012; 50(1): 57-72. doi: 10.1055/s-0031-1282015.

10. Sanchez-Tapias JM, Diago M, Escartin P, Enriquez J, Romero-Gomez M, Bárcena R, et al. Peginterferon-alfa2a plus ribavirin for 48 versus 72 weeks in patients with detectable hepatitis $C$ virus RNA at week 4 of treatment. Gastroenterology. 2006; 131(2): 451-460.

11. Marcellin P, Heathcote EJ, Craxi A. Which patients with genotype 1 chronic hepatitis $\mathrm{C}$ can benefit from prolonged treatment with the 'accordion' regimen? J Hepatol. 2007; 47 (4): 580-587.

12. Marcellin P, Rizzetto M. Response-guided therapy: optimizing treatment now and in the future. Antivir Ther. 2008; 13 Suppl 1: 1-2.

13. Poordad F, McCone J, Bacon BR, Bruno S, Manns MP, Sulkowski MS, et al. Boceprevir for untreated chronic HCV genotype 1 infection. N Engl J Med. 2011; 364(13): 1195-1206. doi: 10.1056/NEJMoa1010494.

14. Jacobson IM, McHutchison JG, Dusheiko G, Di Bisceglie AM, Reddy $\mathrm{KR}$, Bzowej NH, et al. Telaprevir for previously untreated chronic hepatitis C virus infection. N Engl J Med. 2011; 364(25): 2405-2416. doi: 10.1056/NEJMoa1012912.

15. Manns M, Marcellin P, Poordad F, de Araujo ES, Buti M, Horsmans Y, et al. Simeprevir with pegylated interferon alfa $2 \mathrm{a}$ or $2 \mathrm{~b}$ plus ribavirin in treatment-naive patients with chronic hepatitis $C$ virus genotype 1 infection (QUEST 2): a randomised, double-blind, placebo-controlled phase 3 trial. Lancet. 2014 ; 384(9941) : 414-426. doi: 10.1016/ S0140-6736(14)60538-9.

16. Hunyady B, Makara M, Gervain J, Horvath G, Szalay F, Tornai I. Treating naive chronic hepatitis $C$ patients with dual (peginterferon/ribavirin, SOC) or triple (SOC + protease inhibitor, PI) therapy in Hungary. An approach with limited resources. J Hepatol. 2012; 56 Suppl 2: S440441. doi:10.1016/S0168-8278(12)61130-1.

17. Hunyady B, Gervain J, Horvath G, Makara M, Par A, Szalay F, et al. Diagnosis, treatment and follow-up of hepatitis C-virus related liver disease. Hungarian national consensus guideline. Orv Hetil. 2014; 155 Suppl: 3-24. doi: 10.1556/OH.2013.29893. 